\title{
Espaço conector no aeroporto internacional de Guarulhos: o campo que excepciona os Direitos Humanos, sob a luz da nova lei de migração (lei \\ $n^{0}$ 13.445/17).
}

\section{Conector in Guarulhos international airport: a camp that excludes Human Rights, under the new migration law (law $n^{\circ} 13.445 / 17$ ).}

Fernanda Bortoletto Martinatti $^{1}$

Amélia do Carmo Sampaio Rossi ${ }^{2}$.

\section{Resumo:}

O presente artigo se propõe a dar visibilidade à existência do espaço "Conector" do Aeroporto Internacional de Guarulhos, analisando-o como um espaço de exceção onde se estabelecem sistemáticas e variadas violações aos direitos humanos. O referencial teórico se dá partir dos pressupostos filosóficos formulados por Hannah Arendt e Giorgio Agamben, cujos conceitos de "campo" e de "direito a ter direitos" se enquadram na mencionada análise. A partir disso, o artigo pretende também observar as mudanças normativas trazidas pela Nova Lei de Migração (Lei $n^{0}$ 13.445/17) relacionadas à situação existente no "Conector", analisando se, e em que medida, tais mudanças podem representar um potencial avanço nesse ponto específico.

\section{Palavras-chaves:}

Espaço Conector; estrangeiros; direitos humanos; estado de exceção.

\begin{abstract}
:
This paper aims to analyze the space "Conector" of the International Airport of Guarulhos as a space of exception where the most varied violations of human rights are established. The theoretical reference is based on the philosophical assumptions formulated by

\footnotetext{
${ }^{1}$ Fernanda Bortoletto Martinatti. Bacharel pela Faculdade de Direito da Universidade de São Paulo e pós graduada em Filosofia e Direitos Humanos pela Pontifícia Universidade Católica do Paraná (PUCPR).Endereço:. Email: fb.martinatti@gmail.com

2 Amélia do Carmo Sampaio Rossi. Mestre e Doutora em Direito pela UFPR. Professora da Graduação e Pós Graduação - Mestrado em Direitos Humanos e Políticas Públicas da Pontifícia Universidade católica do Paraná (PUCPR). Email: amiwww.com.br@uol.com.br
} 
Hannah Arendt and Giorgio Agamben, whose concepts of "exception" and "right to rights" match within the respective analysis. After that, the article intend to observe the legislative changes brought by the New Migration Law (Law $n^{\circ} 13.445 / 17$ ) related to the situation that exists in the "Conector", analyzing if, and how, those changes could be considered a potencial progress in the protection of these individuals.

Keywords: "Conector"; Foreigners; human rights;exception state.

\section{INTRODUÇÃO}

A Lei $n^{\circ}$ 6.815/80, conhecida como Estatuto do Estrangeiro, permanecia como um dos resquícios legislativos do período de ditadura militar no Brasil e representava a materialização de uma política migratória que enxergava o estrangeiro como uma ameaça à segurança nacional, e não como um sujeito de direitos. Como tal, as principais características do Estatuto do Estrangeiro eram a burocratização da regularização migratória, a discricionariedade absoluta do Estado, a restrição dos direitos políticos e da liberdade de expressão, além da nítida desigualdade de direitos entre estrangeiros e nacionais. ${ }^{3} \mathrm{~A}$ referida Lei hoje encontra-se revogada, sendo substituída pela nova Lei de Migração, publicada em 25 de maio de 2017. Dentre as situações de violações aos direitos dos imigrantes que eram respaldadas pelo Estatuto do Estrangeiro chama atenção a situação de estrangeiros em trânsito, materializada na existência de locais como o "Espaço Conector" no Aeroporto de Guarulhos.

Durante os últimos anos, diversas denúncias noticiaram a existência do chamado "Espaço Conector". Ali, ficavam os estrangeiros inadmitidos no país, primordialmente aqueles com algum problema em sua documentação, detidos sob a custódia da Polícia Federal, por tempo indeterminado e em uma estrutura física precária, antes de serem repatriados a seus países de origem. Ocorre que a detenção de tais pessoas não encontrava regulamentação legal e, apesar de tolher a liberdade de ir e vir dos estrangeiros inexistia qualquer comunicação com as autoridades judiciárias e fiscalização pelas mesmas,

\footnotetext{
${ }^{3}$ VENTURA, Deisy. Criação de lei de migrações é dívida histórica do Brasil. Carta Capital. 21 de agosto de 2014. Disponível em: https://www.cartacapital.com.br/sociedade/divida-historica-uma-lei-de-migracoespara-o-brasil-9419.html
} 
ficando os estrangeiros sujeitos ao arbítrio da Polícia Federal, a qual decidia de maneira soberana seu destino; decidindo, inclusive, sobre eventual repatriação dos inadmitidos.

A análise da estrutura político-jurídica de locais como o "Conector" encontra paralelos na análise realizada pelo filósofo Giorgio Agamben ao tratar da estrutura dos campos de concentração nazistas que institucionalizavam um local de exceção, no qual o ordenamento jurídico não é aplicado e a lei traduz-se unicamente na vontade soberana que detém pleno poder de gerir a vida humana ali existente.

A situação dos estrangeiros no "Conector" também se relaciona com a análise realizada pela filósofa Hannah Arendt sobre a falha no discurso dos direitos humanos quando da proteção dos direitos daqueles que perderam seu status político, como era o caso da massa de apátridas e refugiados no contexto Pós-Segunda Guerra Mundial. Para estes, a perda da cidadania implicava na consequente perda de todos os seus direitos humanos e suas violações, além de serem sistematicamente perpetradas, sequer podiam ser denunciadas, dado que, juridicamente, essas pessoas não existiam como cidadãos.

Dessa forma, o presente artigo pretende analisar, sob o ponto de vista filosófico e hermenêutico, em que medida a detenção de estrangeiros em locais como o "Conector" institucionalizaria um local de anomia jurídica: um "campo" da modernidade no conceito trabalhado por Giorgio Agamben e uma situação de atentado contra a dignidade da pessoa humana, como trabalhado pela filósofa Hannah Arendt. E, sob o ponto de vista jurídico, pretende-se analisar em que medida as mudanças normativas trazidas pela nova Lei de Migração (Lei no 13.445/2017) podem caracterizar um potencial avanço na situação existente no "Conector" durante a vigência do antigo Estatuto do Estrangeiro.

\section{A Lei 6.815/80 E O IMPEDIMENTO DA ENTRADA DE ESTRANGEIROS}

A admissão de estrangeiros em território nacional é ato de soberania do Estado, com a decisão do agente público quanto a seu impedimento de entrada sendo ato discricionário de exercício da soberania do país. ${ }^{4}$

${ }^{4}$ RAMOS, Alan Alexandrino (2015), O impedimento e a repatriação de estrangeiros no Brasil e possíveis inconsistências com a convenção americana de direitos humanos, in Revista Migrações, Outubro 2015, n. ${ }^{\circ}$ 12, Lisboa: ACM, pp. 137-156. Disponível em: <http://www.om.acm.gov.pt/documents/58428/340194/pp137-156_artigo-6.pdf/c252b8dd-93a8-42549243-0dec335b942f)>. Acesso em: 16 abr 2017. 
No Brasil, tal ato discricionário compete à Polícia Federal, que é responsável pela fiscalização das fronteiras nacionais, ficando a critério da autoridade policial decidir sobre.

As hipóteses de inadmissão de estrangeiro estão previstas no artigo 51 do Decreto Lei $\mathrm{n}^{\mathrm{o}} 86.715 / 81^{5}$, que trata basicamente dos requisitos formais que abarcam " $o$ estrangeiro indocumentado ou que não possui visto para ingressar no País ou aquele que apresenta visto divergente da finalidade para a qual veio ao Brasil"6. As hipóteses nas quais não serão concedidos vistos aos estrangeiros estavam, a seu turno, previstas no artigo $7^{\circ}$ da antiga Lei $6.815 / 80^{7}$.

$\mathrm{O}$ ato discricionário de impedimento de entrada de estrangeiros, entretanto, não se limita tão somente aos critérios objetivos acima mencionados. Como preconizava o artigo 26 da Lei 6.815/80, o visto concedido pela autoridade consular configura mera expectativa de direito, e a entrada do estrangeiro pode ser obstada pela inconveniência de sua presença no território nacional.

Caso a autoridade entendesse pela inadmissão do estrangeiro, em regra, o imigrante seria repatriado ao seu país de origem ou de procedência, com exceção daqueles que, ao chegarem ao território nacional, expressassem sua vontade de solicitar seu reconhecimento como refugiados ${ }^{8}$.

Neste ponto reside uma situação delicada que merece ser destacada. O $\S 1^{\circ}$ do artigo $7^{\circ}$ do Estatuto dos Refugiados prevê expressamente que "em hipótese alguma será efetuada sua deportação para fronteira de território em que sua vida ou liberdade esteja

5 BRASIL, Decreto Lei $\mathbf{n}^{\mathbf{0}} \mathbf{8 6 . 7 1 5 / 8 1}$, de 10 de dezembro de 1981. Disponível em: <http://www.planalto.gov.br/ccivil_03/decreto/antigos/d86715.htm>. Acesso em: 16 abr 2017.

${ }^{6}$ Informação existente no website do Ministério de Justiça e Segurança Pública do Brasil. Disponível em: <http://www.justica.gov.br/seus-direitos/migracoes/medidas-compulsorias/deportacao-e-repatriacao >.

Acesso em: 16 abr 2017.

${ }^{7}$ Art. $7^{\circ}$ da Lei 6.815/80. "Não se concederá visto ao estrangeiro:I - menor de 18 (dezoito) anos, desacompanhado do responsável legal ou sem a sua autorização expressa;II - considerado nocivo à ordem pública ou aos interesses nacionais; III - anteriormente expulso do País, salvo se a expulsão tiver sido revogada;IV - condenado ou processado em outro país por crime doloso, passível de extradição segundo a lei brasileira; ouV - que não satisfaça às condições de saúde estabelecidas pelo Ministério da Saúde”. BRASIL. Lei $\mathbf{6 . 8 1 5 / 8 0}$, de 19 de agosto de 1980.Disponível em: <http://www.planalto.gov.br/ccivil_03/leis/L6815.htm>. Acesso em: 16 abr 2017.

${ }^{8}$ Art. $7^{\circ}$ do Estatuto dos Refugiados. "O estrangeiro que chegar ao território nacional poderá expressar sua vontade de solicitar reconhecimento como refugiado a qualquer autoridade migratória que se encontre na fronteira, a qual lhe proporcionará as informações necessárias quanto ao procedimento cabível.

$\S 1^{\circ}$ Em hipótese alguma será efetuada sua deportação para fronteira de território em que sua vida ou liberdade esteja ameaçada, em virtude de raça, religião, nacionalidade, grupo social ou opinião política.”. BRASIL, Lei no 9474/97, de 22 de julho de 1997. Disponível em:

<http://www.planalto.gov.br/ccivil_03/leis/L9474.htm. >. Acesso em: 16 abr 2017. 
ameaçada, em virtude de raça, religião, nacionalidade, grupo social ou opinião política". Tal análise meritória fica a cargo única e exclusivamente da autoridade policial. Isto pode implicar em devoluções indevidas de um imigrante fugindo de uma situação de violação de direitos fundamentais e que deseje eventualmente solicitar refúgio no Brasil ${ }^{9}$, constituindo grave violação do princípio internacional do non refoulement ${ }^{10}$.

Esta repatriação dos estrangeiros inadmitidos, em tese, ocorreria imediatamente e à custa da transportadora, uma vez que a companhia aérea se obriga a permitir o embarque somente daqueles identificados e com vistos válidos ${ }^{1112}$.

Além da complicada análise meritória acerca da repatriação, diversas circunstâncias fáticas podem impedir a repatriação imediata do imigrante, gerando uma situação de limbo jurídico, em que o estrangeiro não está autorizado nem a entrar no país, nem a deixá-lo. ${ }^{13} \mathrm{Na}$ prática, observa-se que, enquanto esperam sua repatriação, os estrangeiros permanecem detidos em zonas primárias de fronteiras, como aeroportos, sem qualquer estrutura física para sua estada, por tempo indeterminado e sem acesso a um defensor público e à ampla defesa.

Sem base legal ${ }^{14}$ para tal cerceamento de liberdade, surgem, então, questionamentos quanto à natureza jurídica dessa detenção e se esta retenção constitui

${ }^{9}$ CHIARETTI, Daniel. Breve Análise da Detenção Migratória no Brasil. Carta Capital. 29 de outubro de 2015. Disponível em: <http://justificando.cartacapital.com.br/2015/10/29/breve-analise-da-detencaomigratoria-no-brasil/>. Acesso em: 16 abr 2017.

${ }^{10}$ O princípio do non refoulement está consagrado no Artigo 33 da Convenção Relativa ao Estatuto dos Refugiados, adotada em 28 de julho de 1951, no âmbito das Nações Unidas. Disponível em:<http://www.acnur.org/t3/fileadmin/Documentos/portugues/BDL/Convencao_relativa_ao_Estatuto_dos Refugiados.pdf $>$ Acesso em: 16 abr 2017.

${ }^{11}$ Artigo 27, Lei 6.815/80, id.

${ }^{12}$ BRASIL. Secretaria Nacional de Justiça (SNJ). Manual de extradição. Brasília: Secretaria Nacional de Justiça (SNJ), Departamento de Estrangeiros, 2012. Disponível em:<https://www.justica.gov.br/suaprotecao/cooperacao-internacional/extradicao/arquivos/manualextradicao.pdf>. Acesso em: 16 abr 2017. ${ }^{13}$ Palavras do Procurador Federal dos Direitos do Cidadão, Aurélio Rios, em entrevista. Agência Brasil. 28 de janeiro de 2015. Disponível em: <http://agenciabrasil.ebc.com.br/internacional/noticia/2015-01/acordomelhora-atendimento-refugiados-e-estrangeiros-no-aeroporto-de>. Acesso em: 16 abr 2017.

${ }^{14}$ Nesse ponto, válido frisar que, com o advento da Constituição Federal de 1988 e a redação do artigo $5^{\circ}$, LXI, da CF/88, a prisão administrativa do estrangeiro para fins de expulsão e deportação passou a terque ser demonstrada e fundamentada mediante decisão da autoridade judiciária, e não mais da autoridade administrativa. Nesse sentido o paradigmático julgado do Superior Tribunal de Justiça, bem como o entendimento atual consolidado, in verbis: "CONSTITUCIONAL. CUSTODIA DE ESTRANGEIRO, MEDIANTE LIBERDADE VIGIADA, PARA FIM DE EXPULSÃO, DECRETADA ADMINISTRATIVAMENTE PELO MINISTRO DA JUSTIÇA. SENDOALIBERDADEVIGIADA UMA FORMA DE CONFINAMENTO, PORTANTO UMA RESTRIÇÃOA LIBERDADE DE IR E VIR, APLICA-SE-LHE MUTATIS MUTANDIS A EXIGENCIACONSTITUCIONALDECOMPETENCIAEXCLUSIVADOPODER JUDICIARIO PARA DECRETA-LA (ART. 5., LXI, DA CONSTITUIÇÃO FEDERAL). CONCESSÃO DE ORDEMDEHABEASCORPUS DE OFICIO PARA DETERMINAR A 
uma forma de prisão. Ademais, sem um status jurídico definido às pessoas nessa condição, é possível garantir o respeito aos seus direitos humanos?

\section{2. “CONECTOR": UM DEPÓSITO DE ESTRANGEIROS NO AEROPORTO INTERNACIONAL DE GUARULHOS}

O Aeroporto Internacional de Guarulhos, situado na região metropolitana da cidade de São Paulo, é responsável pelo maior fluxo de passageiros da América Latina ${ }^{15}$ e, como tal, tem enfrentado de maneira crescente o problema relacionado aos estrangeiros inadmitidos no Brasil, sua repatriação e sua detenção provisória, questão materializada na existência caótica do chamado "Espaço Conector".

$\mathrm{O}$ "Conector" trata-se de uma pequena sala no espaço entre o desembarque e a imigração no Aeroporto Internacional de Guarulhos. Como mencionado, os estrangeiros ali detidos são pessoas inadmitidas de entrar no Brasil, primordialmente pessoas com algum problema em sua documentação e que não podem, por isso, seguir viagem. Isso abarca tanto estrangeiros que possuem o Brasil como destino final, como aqueles para os quais o Brasil seria somente o país de trânsito e que, por alguma razão, foram impossibilitados pela companhia aérea de embarcar até o destino final. Também podem ficar detidos no "Conector" aqueles estrangeiros que suscitam alguma suspeita ou que simplesmente não são capazes de se comunicar o bastante para explicar a sua situação ${ }^{16}$.

Como resultado, eles ficam ali detidos, sem possibilidade de comunicação externa ou contato com a Defensoria Pública da União.

Isto porque, como não estão presos sob um ponto de vista jurídico, eis que não cometeram nenhum delito, os estrangeiros não têm garantidos os direitos constitucionais do devido processo legal e de ampla defesa. Na prática, ao contrário, têm sua liberdade cerceada, visto que não podem deixar o recinto e encontram-se sob a vigilância da Polícia Federal.

CASSAÇÃODASRESTRIÇÕESIMPOSTAS ADMINISTRATIVAMENTE AO PACIENTE, ATE QUE O JUIZ COMPETENTE DECIDA A RESPEITO.(Com 1/DF, Rel. Ministro CARLOS THIBAU, Rel. p/ Acórdão Ministro ASSIS TOLEDO, CORTE ESPECIAL, julgado em 14/09/1989, DJ 12/03/1990, p. 1696)"

${ }^{15}$ Dados extraídos de Relatório Operacional do Aeroporto Internacional de Guarulhos. Disponível em: $<$ https://www.gru.com.br/pt/RelatorioOperacional/2016-12.pdf. $>$. Acesso em: 16 abr 2017.

${ }^{16}$ ASANO, Camila. Migrantes em Guarulhos. Conectas Direitos Humanos. 18 de dezembro de 2014. Disponível em: <http://www.conectas.org/pt/acoes/politica-externa/noticia/27625-migrantes-emguarulhos >. Acesso em: 16 abr 2017. 
O Alto Comissariado das Nações Unidas para Refugiados considera detenção migratória qualquer confinamento em unidades de trânsito, como aeroportos, nos quais haja uma restrição substancial da liberdade de movimentação e a única oportunidade de deixar a área limitada seja o abandono do próprio território ${ }^{17}$. A situação que ocorre no “Espaço Conector" claramente enquadra-se nessa categoria.

Existe, portanto, uma verdadeira aberração jurídica, na qual a falta de previsão legal da existência de tal detenção migratória não impede que o direito de ir e vir dos imigrantes seja tolhido, mas impede que estes tenham acesso aos direitos constitucionalmente previstos a todos aqueles em restrição de liberdade ${ }^{18}$.

Os dados oficiais são poucos, uma vez que a Polícia Federal detém controle total sobre as informações dos estrangeiros ali detidos ${ }^{19}$, porém, existem relatos de pessoas estrangeiras que permaneceram por até três meses ${ }^{20}$ detidas no "Conector".

Ao longo dos anos, a situação no "Conector" tem chamado atenção e atraído diversas denúncias de órgãos judiciários e organizações não governamentais que militam pelos direitos humanos e direitos dos migrantes, dando visibilidade às sistemáticas violações dos direitos humanos das pessoas ali detidas.

Relatos jornalísticos ${ }^{21}$ noticiam a detenção de estrangeiros, incluindo famílias inteiras, com mulheres grávidas e crianças, em condições absolutamente precárias. Em

\footnotetext{
${ }^{17}$ ASANO, Camila. Migrantes em Guarulhos. Conectas Direitos Humanos. 18 de dezembro de 2014. Disponível em: <http://www.conectas.org/pt/acoes/politica-externa/noticia/27625-migrantes-emguarulhos $>$. Acesso em: 16 abr 2017.

${ }^{18} \mathrm{O}$ artigo $7^{\circ}$ e $8^{\circ}$ da Convenção Interamericana de Direitos Humanos preveem os direitos daqueles em restrição de liberdade, valendo-se ressaltar que: "Ninguém pode ser submetido a detenção ou encarceramento arbitrários"; "Toda pessoa privada da liberdade tem direito a recorrer a um juiz ou tribunal competente, a fim de que este decida, sem demora, sobre a legalidade de sua prisão ou detenção e ordene sua soltura se a prisão ou a detenção forem ilegais. “. Convenção Americana de Direitos Humanos de 22 de novembro de 1969. Disponível em: $<$ https://www.cidh.oas.org/basicos/portugues/c.convencao_americana.htm>. Acesso em 16 abr 2017.

${ }^{19}$ A Organização Não Governamental Conectas, baseada na Lei de Acesso à Informação, efetuou um pedido de acesso aos dados relativos ao funcionamento do Conector, sendo que a Polícia Federal ainda não os disponibilizou. Disponível em:<http://www.conectas.org/pt/acoes/justica/lei-de-acesso-a-informacao/99pedido-lai-a-policia-federal-sobre-o-espaco-conector-no-aeroporto-internacional-de-guarulhos $>$. Acesso em 16 abr 2017.

20 “Exemplo dessa situação foi vivenciada em 2007 pela coordenadora geral do Posto, a qual foi solicitada pela Polícia Federal para colaborar no caso de um passageiro somali que estava no conector há 3 meses, sem conseguir retornar ao país de origem." In: Sistematização da experiência de um ano de funcionamento do posto, Ministério da Justiça. Disponível em: <http://www.justica.gov.br/sua-protecao/trafico-depessoas/publicacoes/anexos/sistematizacaofuncionamentopostohumanizado.pdf

${ }^{21}$ FARIAS, Adriana. Em busca de refúgio, estrangeiro fica 20 dias retido em aeroporto. Folha de São Paulo. 14 de junho de 2014. Disponível em: <http://www1.folha.uol.com.br/cotidiano/2014/06/1470333em-busca-de-refugio-estrangeiro-fica-20-dias-retido-em-aeroporto.shtml> Acesso em 16 abr 2017. Conector volta a mostrar situação precária de migrantes no Brasil e necessidade de nova lei de migração. Migra Mundo. 29 de setembro de 2016. Disponível em: <http://migramundo.com/conector-volta-a-
} 
novembro de 2014, por exemplo, organizações não governamentais noticiaram que mais de vinte pessoas eram mantidas no "Conector" há mais de 40 dias, dormindo no chão, sem falar com ninguém, com acesso restrito a informações acerca das razões de sua detenção e de suas perspectivas futuras e sem acesso à alimentação adequada e suficiente ${ }^{22}$. Alguns deles relataram estar sobrevivendo à base de água e açúcar e estar passando por problemas médicos em decorrência disso ${ }^{23}$.

A situação é ainda mais delicada ao considerar-se o fluxo migratório de solicitantes de refúgio pelo qual vêm passando o Brasil. Dentro deste cenário, o Aeroporto de Guarulhos é também uma das principais portas de entrada para solicitantes de refúgio no país. Segundo dados divulgados pelo ACNUR $^{24}$ (Alto Comissariado das Nações Unidas para Refugiados), entre os cerca de 9,2 mil estrangeiros que pediram refúgio às autoridades brasileiras em 2014, aproximadamente 1.000 entraram pelo referido aeroporto.

Diante disso, o fluxo migratório misto ${ }^{25}$ que passa pelo "Conector" demanda uma atuação sensível na compreensão global da situação dos estrangeiros.

Os relatos e dados de estrangeiros, ao contrário,evidenciam a falta de qualificação dos profissionais da Polícia Federal para a atuação perante os estrangeiros em situação de vulnerabilidade.

Um acompanhamento feito pelo ACNUR em conjunto com a CASP aponta o registro de 74 pessoas que ficaram retidas no "Conector", a despeito de haverem manifestado temor de regressarem a seus países de origem. Dessas, 15 foram repatriadas,

mostrar-situacao-precaria-de-migrantes-no-brasil-e-necessidade-de-nova-lei-de-migracao/>. Acesso em 16 abr 2017.

${ }^{22}$ A alimentação do estrangeiro fica a cargo da transportadora que o trouxe até o Brasil. As mencionadas denúncias apontam, entretanto, que, como muitos se recusam a dizer em qual voo chegaram, acabam ficando sem alguém que se responsabilize por alimentá-los.

${ }^{23} \mathrm{O}$ estrangeiro nigeriano B.O, de 45 anos, retido no Conector havia dois dias, dizia sofrer de diabetes, sem poder ter acesso à insulina que estava em sua bagagem. (In: SANCHES, Mariana. Candidatos a refúgio ficam no limbro em sala do Aeroporto. O Globo. 21 de junho de 2015. Disponível em: <http://oglobo.globo.com/brasil/candidatos-refugio-ficam-no-limbo-em-sala-de-aeroporto-16509800>. Acesso em 16 abr 2017.

${ }^{24}$ GODINHO, Luiz Fernando. Acordo melhora atendimento a refugiados e estrangeiros no Aeroporto de Guarulhos. ACNUR. 29 de janeiro de 2015. Disponível em: http://www.acnur.org/portugues/noticias/noticia/acordo-melhora-atendimento-a-refugiados-e-estrangeirosno-aeroporto-de-guarulhos/. Acesso em 16 abr 2017.

25 Fluxo migratório misto refere-se a movimentos populacionais complexos que incluem refugiados, requerentes de asilo, migrantes econômicos e outros migrantes em situações particulares como tráfico de pessoas, contrabando de migrantes, entre outros. (in: TERESI, Verônica Maria. Guia de referência para a rede de enfrentamento ao tráfico de pessoas no Brasil. Ministério da Justiça, Secretaria Nacional de Justiça, 2012, pág. 37). 
33 registraram solicitação de refúgio e 4 foram autorizadas a continuar viagem para outro país. Das 22 restantes, não há informações sobre terem entrado no país ou terem sido repatriadas. Tais pessoas eram nacionais da Eritréia, da Somália, do Paquistão,da Síria, do Butão e dos Camarões, todos países que apresentam realidades favoráveis à possibilidade de concessão de refúgio. É importante ressaltar que, destas 74 pessoas cuja detenção foi registrada, 8 eram menores de $18 \operatorname{anos}^{26}$. Os números, em realidade, devem ser maiores, posto que, pelas já mencionadas dificuldades de comunicação com o mundo exterior dentro do "Conector", nem todos os casos chegam ao conhecimento das instituições.

Considerando a situação de alguns desses estrangeiros, uma repatriação sumária pode equivalera uma sentença à pena de morte. Como ilustração, destaca-se um caso ocorrido em $2005^{27}$. Um passageiro vindo de Santiago do Chile desembarcou em São Paulo apresentando passaporte coreano. Ao ser inquirido sobre sua permanência no Brasil, onde ficaria, o motivo de sua vinda do Chile e se falava inglês para se comunicar, não conseguiu responder. Foi encontrada no aeroporto uma pessoa coreana que poderia realizar a tradução entre a Polícia Federal e o passageiro em questão; a comunicação não foi possível, revelando assim que, em realidade, o passageiro não era coreano e, portanto, seu passaporte era falso e sua origem, desconhecida. Esse fato impossibilitava sua repatriação para o país de procedência, no caso, o Chile, dado que não poderia embarcar com documento falso e também impossibilitava sua repatriação para seu país de origem, eis que este era desconhecido. O passageiro foi levado ao "Conector", onde ficou detido enquanto a equipe policial trabalhava comunicando-se com as embaixadas, com o fito de encontrar o país de origem do cidadão. Infrutífera qualquer tentativa de que o homem contasse de onde efetivamente vinha, o Delegado de Polícia Federal decidiu, então, enviá-lo para o país oriental que o estrangeiro havia esboçado melhor entendimento da língua pátria com a pessoa do consulado. Neste momento, o estrangeiro mostra-se desesperado e começa a chorar dizendo, em um inglês raso, que não ia para lá, aduzindo

\footnotetext{
${ }^{26}$ LEITE, Larissa. O devido Processo legal para o refúgio no Brasil. Doutorado-Faculdade de Sireito, Universidade de São Paulo, Dezembro de 2014. Disponível em < http://www.teses.usp.br/teses/disponiveis/2/2140/tde-08042016-145056/pt-br.php>Acesso em 16 abr 2017. ${ }^{27}$ LESSA, Paula Constantino Chagas. Direitos Humanos do estrangeiro em trânsito. Uma perspectiva entre a soberania e os Direitos Humanos do Estrangeiro em trânsito. Revista Publica Direito. Disponível em <http://www.publicadireito.com.br/artigos/?cod=19a87049ef104ba1 >. Acesso em 16 abr 2017.
} 
que iriam matá-lo. Mesmo após tais afirmações, o estrangeiro foi repatriado para este país e o seu destino lá é desconhecido.

Outro caso emblemático ocorreu em 2014, envolvendo dois homens e uma mulher cidadãos da Eritréia ${ }^{28}$. Os três irmãos permaneceram detidos no "Conector" e, ao receberem a notícia de que seriam deportados, os homens teriam entravado luta corporal com os policiais federais, afirmando que, caso fossem devolvidos, seriam submetidos a tortura e sujeitos à pena de morte ${ }^{29}$, porque haviam desertado de um sistema de recrutamento forçado e quase vitalício do Exército, imposto pelo governo de seu país. Devido à reação física dos homens, um boletim de ocorrência foi lavrado em seu desfavor e, assim, com acesso à Defensoria Pública da União, puderam pleitear o pedido de refúgio. A irmã, ao contrário, foi sumariamente repatriada e não se têm notícias de seu destino. ${ }^{30}$

Vê-se, assim, que a Polícia Federal age segundo uma lógica da "palavra mágica", segundo a qual é necessário que a pessoa seja explícita acerca de sua vontade de instauração do procedimento de reconhecimento de refúgio, desconsiderando outras circunstâncias fáticas que indiquem o perigo decorrente de uma eventual repatriação. Nega-se o possível direito a refúgio que lhe seria cabível pelo mero fato de o estrangeiro desconhecer a palavra jurídica que o protegeria em tal situação.

Mais do que o despreparo ${ }^{31}$ dos agentes policiais na atuação com estrangeiros, as violações de direitos humanos perpetradas no "Conector" (incluindo-se aqui tanto o

\footnotetext{
${ }^{28}$ SEVERO, Fabiana Galero. O procedimento de solicitação de refúgio no Brasil à luz da proteção internacional dos diretos humanos. R. Defensoria Públ. União. Brasília, DF n. 8 p. 1-356 jan/dez. 2015. Disponível emhttp://www.dpu.def.br/images/stories/escola_superior/arquivos/Revista/revista-8/artigo2_fabiana-galera-severo.pdf. Acessoem 16 abr 2017.

${ }^{29}$ Article 300 of the Penal Code of 1991 of Eritrea stipulates that desertion is punishable by a term of imprisonment of up to five years. During wartime, the term of imprisonment varies between five years and life imprisonment; in serious cases, the death penalty is imposed. <https://www.easo.europa.eu/sites/default/files/publications/COI-\%20Eritrea-Dec2016_LR.pdf >In countries such as Eritrea, Malaysia, North Korea and Syria, very little information about the use of the death penalty is available due to restrictive state practice or political instability. Disponível em $<$ https://www.amnesty.org/en/latest/news/2015/04/death-penalty-607-executions-the-story-behind-thenumbers/>

${ }^{30}$ Leite, Larissa. Ibidem.

${ }^{31}$ Note-se que uma atuação sensível do agente perante a situação dos estrangeiros é vital. Em material da ACNUR existem instruções do comportamento no tratamento de possíveis solicitantes de refúgio, in verbis: "Se o estrangeiro é detido e no procedimento de repatriação demonstra um excessivo temor de retornar ao país de origem, algum problema pode estar acontecendo, sendo fundamental que a Polícia Federal tenha a cautela de aferir, de indagar desse estrangeiro, qual é seu histórico de vida, verificar sua nacionalidade, sua etnia, de onde ele provém, se a região de origem do estrangeiro é uma região conflituosa, se está passando por algum quadro de exceção, dentre outras coisas. A partir daí, certamente, o policial terá condições de melhor identificar esse estrangeiro e dar condução ao processo. Essa autoridade competente,
} 
cerceamento de liberdade sem base legal que é nele regulamentado, quanto a repatriação sumária de indivíduos que poderiam ser enquadrados como solicitantes de refúgio) vão ao encontro de uma política nacional migratória, materializada especialmente no Estatuto do Estrangeiro (Lei $n^{\circ}$ 6.815/80) que enxergava o estrangeiro como ente perigoso, sob o ponto de vista de preservação da segurança nacional, em detrimento de seus direitos humanos ${ }^{32}$.

\section{3. “CONECTOR” COMO “CAMPO” DA MODERNIDADE, SEGUNDO A VISÃO DE GIORGIO AGAMBEN}

Os migrantes detidos no Conector concretizam a existência de um ponto de tensão entre, de um lado, o discurso e a prática de proteção à segurança nacional e, de outro, a proteção aos direitos do indivíduo.

Essa discussão, entretanto, não é recente. O filósofo Giorgio Agamben ${ }^{33}$ já apontava que a classificação de grupos sociais considerados perigosos à ordem e à sociedade era o que permitia que pessoas tivessem seus direitos total ou parcialmente suspensos. A definição dos critérios para a catalogação de uma vida humana como perigosa advém do exercício do poder soberano e, uma vez assim definida, a vida

ao perceber que o estrangeiro tem essa vontade de solicitar proteção internacional, ou tem fundado temor de voltar ao país de origem, deve notificar esse solicitante a prestar declarações." Refúgio no Brasil: a proteção brasileira aos refugiados e seu impacto nas Américas / Luiz Paulo Teles Ferreira Barreto, organizador. - 1. ed. - Brasília: ACNUR, Ministério da Justiça, 2010.Disponível em: http://www.acnur.org/t3/fileadmin/Documentos/portugues/Publicacoes/2010/Refugio_no_Brasil.pdf Acesso em 16 abr 2017.

${ }^{32}$ Em entrevista, o Delegado de Polícia Federal do Aeroporto de Guarulhos chamou atenção para o fato de que refugiados estavam se utilizando de seu status para o cometimento de delitos como o tráfico transnacional de drogas. "Não estamos fazendo ilação. É um fato e nos chamou atenção. Temos uma lei que salva vidas, mas um fato que se originou dessa lei é que muitos refugiados estão sendo cooptados pelo narcotráfico ou já vieram de seus países com a intenção de cometer crime-afirma o delegado". A Defensoria Pública da União, ao contrário, questiona a motivação da divulgação pela Polícia Federal de casos de tráfico de drogas envolvendo solicitantes de refúgio, eis que, segundo alegam, as "mulas" que fizeram pedido de refúgio representam $0,2 \%$ do total de solicitantes do ano passado. "É um número irrisório. Qual é o propósito da PF de divulgar esse tipo de informação que pode disseminar grande preconceito contra os refugiados e nem é significativa sobre a realidade dessa população?" "A PF faz uso dessas prisões para justificar a existência do Conector. Na prática, é a própria PF que está decidindo quem pode ou não pedir refúgio-afirma o defensor público". (in. SANCHES, Mariana. Candidatos a refúgio ficam no limbro em sala do Aeroporto. O Globo. Id)

${ }^{33}$ AGAMBEN, Giorgio. Homo sacer: O poder soberano e a vida nua, I. 2. Ed. Belo Horizonte: Ed. UFMG, 2010. 
humana poderia ser colocada em uma situação de exceção e, daí, impreterivelmente, em algum tipo de "campo".

Suas teses mostram-se pertinentes para compreendermos a existência moderna de lugares de completa anomia jurídica, como é o caso do "Conector". Para ele, a discussão em torno dos campos de concentração nazistas não deveria centrar-se exclusivamente nos horrores ali perpetrados, mas, sim, na análise de sua estrutura político-jurídica, que, longe de ser uma irracionalidade do nazismo, pode ser encontrada com frequência na sociedade moderna.

Segundo o filósofo italiano, o "campo" representa o espaço geográfico onde o ordenamento jurídico está suspenso e, em seu lugar, se coloca a vontade soberana. No campo, a vontade soberana coincide com a lei e a exceção se torna a regra; o estado de exceção, essencialmente uma suspensão temporal do ordenamento com base numa situação factícia de perigo, adquire uma disposição espacial permanente, fora do ordenamento normal e com absoluta independência de todo controle judiciário.

Assim, para o autor, estamos diante de um campo toda vez que é criada uma estrutura que materializa o estado de exceção e um espaço onde a vida humana está sujeita irrestritamente ao poder soberano, independentemente da natureza dos crimes que ali são cometidos. ${ }^{34}$ Dessa forma, a caracterização de um campo não passa necessariamente pelo extermínio, mas, sim, por um espaço no qual o ordenamento jurídico normal é suspenso de fato e o cometimento ou não de atrocidades não depende do direito, mas somente da civilidade e do senso ético da polícia que age provisoriamente como soberana.

Essa caracterização enquadra perfeitamente com o "Espaço Conector". O poder soberano ali é exercido pela Polícia Federal, que define arbitrária e exclusivamente a aplicação dos critérios subjetivos na escolha daqueles que serão detidos no "Conector" e como estes serão tratados. As justificativas da Polícia Federal de que "não estamos

\footnotetext{
${ }^{34} \mathrm{O}$ próprio autor aponta que as zones d'attente nos Aeroportos Internacionais franceses, nas quais são retidos por quatro dias antes da intervenção da autoridade judiciária estrangeiros que pedem o reconhecimento do estatuto do refugiado, são exemplos de campos da modernidade. In:< AGAMBEN, Giorgio. Idem.)
} 
maltratando ninguém aqui" ${ }^{35}$, ainda que fossem reais, mostrariam apenas o senso ético da polícia, não eximindo a anomia jurídica existente no local ${ }^{36}$.

Ainda, como bem aponta Agamben, a base jurídica do internamento nos campos de concentração não era o direito comum, mas sim um estatuto jurídico classificado como uma "medida policial preventiva", na medida em que permitia tomar sob custódia certos indivíduos independentemente de qualquer conduta penalmente relevante, unicamente com o fim de evitar um perigo para a segurança do Estado.

No caso do "Conector", vê-se exatamente a contenção dos estrangeiros com o fito de proteção da segurança nacional, muitas vezes demonstrando um preconceito de origem institucionalizado e baseado em estereótipos de periculosidade dos estrangeiros.

Segundo Agamben, no “campo", a vida humana é capturada numa forma de exclusão inclusiva: incluída apenas por estar capturada e submetida à vontade soberana que decretou a exceção, mas completamente excluída dos direitos fundamentais.

No "Conector", acontece exatamente o mesmo no "Conector". Os estrangeiros ali detidos não têm sua condição e status jurídico previsto no ordenamento, o que os impede de ter quaisquer direitos fundamentais resguardados. Ao mesmo tempo em que estão excluídos do ordenamento, entretanto, estão incluídos sob o domínio do poder soberano, em uma nítida inclusão a partir de sua própria exclusão, como fala Agamben. O “Conector” se mostra, assim, um espaço onde o estrangeiro está privado de sua liberdade, sem proteção do Direito Penal.

O campo e o "Conector" distinguem-se, dessa forma, de um simples espaço de reclusão ${ }^{37}$, materializando um espaço de exceção.

\section{CIDADANIA E DIREITOS HUMANOS: UM DiÁlOGO ACERCA DA MODERNIDADE DAS TESES DE HANNAH ARENDT}

\footnotetext{
${ }^{35}$ Fala do Delegado de Polícia Federal em reportagem jornalística sobre o conector. (in. SANCHES, Mariana. Candidatos a refúgio ficam no limbro em sala do Aeroporto. O Globo. Id).

${ }^{36}$ Como tentativa de minimizar as violações de direitos humanos perpetradas no âmbito do Conector, foi assinado um Termo de Cooperação com o fito de "promover soluções humanitárias e solidárias para situações de estrangeiros inadmitidos no Aeroporto de Guarulhos-São Paulo, alocados em área conhecida como Conector". Sua íntegra encontra-se disponível em: <http://www.mpf.mp.br/sala-deimprensa/noticias/noticias-do-site/copy_of_pdfs/convenio-conector-final.pdf>. Acesso em 16 abr 2017. ${ }^{37}$ AGAMBEN, Giorgio. Ibidem. Pag. 22.
} 
Assim como Giorgio Agamben, a filósofa Hannah Arendt $^{38}$ também aponta o "campo" como institucionalização estável da exceção. A perda ou suspensão total de direitos não se limita, entretanto, somente a uma estrutura de um espaço como "campo": a análise da filósofa acerca da questão dos apátridas e dos refugiados no contexto pósPrimeira Grande Guerra também mostra de forma inequívoca a perda total dos direitos ditos sagrados e inalienáveis do homem, uma vez perdida sua cidadania.

Tal discussão também guarda grande pertinência na análise da situação dos estrangeiros no "Conector" e nos traz reflexões importantes, demonstrando como suas palavras não perderam a atualidade.

Hannah Arendt aponta que, no sistema do Estado-nação, os direitos sagrados e inalienáveis do homem que, em tese, provinham somente da natureza humana per se, em realidade, mostram-se desprovidos de qualquer tutela no instante em que não é possível configurá-los como direitos dos cidadãos de um Estado. Isto significa que, perdendo sua cidadania, o indivíduo perde também todos os seus direitos humanos. São o verdadeiro refugo da terra.

A partir dacrítica à falha na proteção dos direitos daqueles que perderam seu status político, a autora aduz que: "Nenhum paradoxo da política contemporânea é tão dolorosamente irônico como a discrepância entre os esforços de idealistas bemintencionados, que persistiam teimosamente em considerar "inalienáveis" os direitos desfrutados pelos cidadãos de países civilizados, e a situação de seres humanos sem direito algum."

Os refugiados e apátridas Pós-Segunda Guerra Mundial, objeto da análise da filósofa, são precisamente estes "seres humanos sem direito algum". Os estrangeiros no "Conector" nos dias atuais, idem. Assim como os refugiados e apátridas analisados por Hannah Arendt, (os quais, com a perda de seu status político, perdem todos os seus direitos humanos) a falta de um status jurídico definido às pessoas detidas no "Conector" permite que as ações ali perpetradas não sejam fiscalizadas e protegidas por nenhuma instituição.Seus direitos humanos são, assim, sistematicamente violados.

Segundo suas teses, o apátrida na qualidade de homem sem Estado, era uma “anomalia para a qual não existia posição apropriada na estrutura da lei geral” e, por

\footnotetext{
38 Apesar de divergirem em partes em suas teses, os autores coincidem ao classificar o campo como institucionalização estável da exceção. Ainda que, para Giorgio Agamben, Hannah Arendt tenha falhado ao não tratar sobre a biopolítica em suas teses, tal ponto não será pormenorizado no presente artigo.
} 
isso, ficava completamente à mercê da polícia. A polícia deixava de ser um instrumento para executar a lei, e passava a ser uma autoridade agindo por conta própria e governando diretamente as pessoas. A discussão centrava-se, assim, em como diminuir a carga de indesirables $^{39}$ no país, tornando-os deportáveis novamente, o que era realizado impreterivelmente, mesmo que o país de origem se recusasse a reconhecer o repatriado em perspectiva como cidadão ou, pelo contrário, desejasse seu retorno apenas para puni$10^{40}$.

O mesmo ocorre até os dias de hoje com os estrangeiros detidos no "Conector". São uma anomalia jurídica não regulamentada pelo ordenamento e, como tal, estão submetidos ao poder discricionário da polícia que busca sua repatriação sumária sem uma análise meritória adequada do eventual perigo que o repatriado poderia sofrer em seu país de origem. Vige no local a noção de caridade e de bom senso da polícia, e não a noção de direitos. Privilégios ou injustiças são dados ao sabor do acaso e sem qualquer relação com o que os estrangeiros fazem, fizeram ou venham a fazer. ${ }^{41}$

Hannah Arendt aponta que a melhor forma de determinar se uma pessoa foi expulsa do âmbito da lei é perguntar-se se, para ela, seria melhor cometer um crime. Em suas valiosas palavras:

Se um pequeno furto pode melhorar a sua posição legal, pelo menos temporariamente, podemos estar certos de que foi destituída dos direitos humanos. Pois o crime passa a ser, então, a melhor forma de recuperação de certa igualdade humana, mesmo que ela seja reconhecida como exceção à norma. O fato - importante - é que a lei prevê essa exceção. Como criminoso, mesmo um apátrida não será tratado pior que outro criminoso, isto é, será tratado como qualquer outra pessoa nas mesmas condições. Só como transgressor da lei pode o apátrida ser protegido pela lei. Enquanto durem o julgamento e o pronunciamento da sua sentença, estará a salvo daquele domínio arbitrário da polícia, contra o qual não existem advogados nem apelações. $O$ mesmo homem que ontem estava na prisão devido à sua mera presença no mundo, que não tinha quaisquer direitos e vivia sob ameaça de deportação, ou era enviado sem sentença e sem julgamento para algum tipo de internação por haver tentado trabalhar e ganhar a vida, pode tornar-se quase um cidadão completo graças a um pequeno roubo. Mesmo que não tenha um

\footnotetext{
${ }^{39}$ ARENDT, Hannah. 1906-1975. Origens do totalitarismo. Tradução: Roberto Raposo- São Paulo: Companhia das Letras. 1989.

${ }^{40}$ AREDNT, Hannah. Ibidem. Pag. 300-336.

${ }^{41}$ AREDNT, Hannah.Ibidem. Pag. 300-336.
} 
vintém, pode agora conseguir advogado, queixar-se contra os carcereiros e ser ouvido com respeito. Já não é o refugo da terra: é suficientemente importante para ser informado de todos os detalhes da lei sob a qual será julgado. Ele torna-se pessoa respeitável. ${ }^{42}$

O que tem acontecido com as pessoas no "Conector" enquadra-se perfeitamente nesta descrição, evidenciando a perda total de seus direitos humanos. O caso citado da cidadã eritréia prova claramente isso. Seus irmãos, por terem cometido um delito, tiveram acesso à Defensoria Pública da União e, a partir disso, tiveram seus direitos de solicitação de refúgio resguardados. A mulher, ao contrário, não tendo cometido um delito, foi sumariamente repatriada, não obstante seu direito de ter sua solicitação de refúgio levada em consideração. Sendo-lhe negado este direito, foram atingidos seus direitos humanos mais básicos, além do devido processo legal, seu direito à integridade física e quiçá o direito à própria vida.

Os citados casos do "Conector"parecem infelizes exceções a uma regra sadia e normal, mas, em realidade, tais exceções não são casuais e mostram a escolha de uma política migratória que os mantêm fora da norma para, assim, priorizar-se a segurança nacional em detrimento dos direitos individuais dos estrangeiros.O mero fato de estarem indocumentados ou serem imigrantes ilegais não pode ser utilizado como justificativa para a violação de seus direitos humanos. ${ }^{43}$

\section{POLÍTICA MIGRATÓRIA E A NOVA LEI 13.445/17.}

$\mathrm{O}$ antigo Estatuto do Estrangeiro evidenciava expressamente a escolha por uma política migratória cujo foco não era o indivíduo estrangeiro, seus direitos e vulnerabilidades. Ao contrário, o artigo $2^{\circ}$ previa expressamente que, na aplicação da Lei atender-se-ia "precipuamente à segurança nacional, à organização institucional, aos

\footnotetext{
${ }^{42}$ AREDNT. Hannah. Ibidem. Pag. 300-336.

${ }^{43}$ Em maio de 2.002, o Estado do México submeteu à Corte Interamericana, requisição de opinião consultiva.O questionamento relaciona-se à proteção dos direitos humanos, especialmente da igualdade e não discriminação,aplicados aos imigrantes ilegais. A Corte posicionou-se aduzindo que os Estados-parte do Pacto de San José têm a obrigação geral de respeitar e garantir os direitos humanos a todos, independentemente de sua situação migratória. Disponível em: < http://www.corteidh.or.cr/docs/opiniones/seriea_18 esp.pdf >. Acesso em 16 abr 2017.
} 
interesses políticos, sócio-econômicos e culturais do Brasil, bem assim à defesa do trabalhador nacional".

A Lei 13.445/17 trouxe uma série de mudanças no que se refere à política migratória brasileira.

$\mathrm{O}$ artigo $3^{\circ}$ da Lei $13.445 / 17$ prevê os novos princípios e diretrizes que devem reger a política migratória brasileira, incluindo dentre eles os direitos humanos, o repúdio à xenofobia e qualquer forma de discriminação, a não criminalização da migração, a acolhida humanitária, entre outros. Com isso, o foco da política migratória brasileira deixa de ser a segurança nacional e passa a ser o indivíduo migrante em sua plenitude de direitos.

As hipóteses nas quais não serão concedidos vistos aos estrangeiros que antes estavam previstas no artigo $7^{\circ}$ da Lei $6.815 / 80^{44}$, passam a constar no artigo $9^{\circ}$ da Lei 13.445/17 ( Lei da Migração), nos seguintes termos: "Não se concederá visto: I - a quem não preencher os requisitos para o tipo de visto pleiteado; II - a quem comprovadamente ocultar condição impeditiva de concessão de visto ou de ingresso no País; ou III - a menor de 18 (dezoito) anos desacompanhado ou sem autorização de viagem por escrito dos responsáveis legais ou de autoridade competente." Dentre as previsões excluídas encontra-se o inciso que aduzia que não seria concedido visto ao estrangeiro "nocivo à ordem pública ou aos interesses nacionais”, que, por seu caráter subjetivo e demasiado aberto, dava margem a uma enorme discricionariedade para a autoridade policial que atuava, ali, como soberana.

As hipóteses de impedimento de estrangeiros também passaram por uma significativa mudança. Enquanto o antigo Estatuto do Estrangeiro previa que, além das hipóteses do art. $7^{\circ}$, o estrangeiro poderia ter sua entrada obstada pela "inconveniência de sua presença no território nacional", a Lei 13.445/17 discriminou de maneira mais objetiva os critérios de impedimento para a entrada do imigrante no país ${ }^{45}$. A

\footnotetext{
${ }^{44}$ Art. $7^{\circ}$ da Lei 6.815/80. "Não se concederá visto ao estrangeiro:I - menor de 18 (dezoito) anos, desacompanhado do responsável legal ou sem a sua autorização expressa;II - considerado nocivo à ordem pública ou aos interesses nacionais;III - anteriormente expulso do País, salvo se a expulsão tiver sido revogada;IV - condenado ou processado em outro país por crime doloso, passível de extradição segundo a lei brasileira; ouV - que não satisfaça às condições de saúde estabelecidas pelo Ministério da Saúde". BRASIL. Lei $\mathbf{6 . 8 1 5 / 8 0}$, de 19 de agosto de 1980.Disponível em: <http://www.planalto.gov.br/ccivil_03/leis/L6815.htm>. Acesso em: 16 abr 2017.

45 "Art. 45. Poderá ser impedida de ingressar no País, após entrevista individual e mediante ato fundamentado, a pessoa:

I - anteriormente expulsa do País, enquanto os efeitos da expulsão vigorarem;
} 
terminologia aberta de "interesse nacional" foi substituída por "ato contrário aos princípios e objetivos dispostos na Constituição Federal", o que mostra-se pertinente já que a justificativa da autoridade policial deixa de ser algo abstrato para dever embasar-se em fatos e atos concretos praticados pelo estrangeiro. Além disso, a antiga Lei 6.815/80 previa, em seu artigo 26, também que a entrada de estrangeiro mesmo sem qualquer ato ou fato a ele relacionado poderia ser impedida tão-somente diante da existência de um membro da família do estrangeiro impedido, previsão que também foi excluída na nova Lei.

Outra mudança bastante significativa que afeta diretamente o regime imposto aos estrangeiros inadmitidos e detenções como as existentes no "Conector" refere-se à nova previsão do artigo 49 da nova Lei de Migração.

O referido artigo prevê que:

"Art. 49. A repatriação consiste em medida administrativa de devolução de pessoa em situação de impedimento ao país de procedência ou de nacionalidade.

$\S 1$ lo Será feita imediata comunicação do ato fundamentado de repatriação à empresa transportadora e à autoridade consular do país de procedência ou de nacionalidade do migrante ou do visitante, ou a quem o representa.

§ 20 A Defensoria Pública da União será notificada, preferencialmente por via eletrônica, no caso do $\S 4$ o deste artigo ou quando a repatriação imediata não seja possível.

II - condenada ou respondendo a processo por ato de terrorismo ou por crime de genocídio, crime contra a humanidade, crime de guerra ou crime de agressão, nos termos definidos pelo Estatuto de Roma do Tribunal Penal Internacional, de 1998, promulgado pelo Decreto $n^{\circ} 4.388$, de 25 de setembro de 2002;

III - condenada ou respondendo a processo em outro país por crime doloso passível de extradição segundo a lei brasileira;

IV - que tenha o nome incluído em lista de restrições por ordem judicial ou por compromisso assumido pelo Brasil perante organismo internacional;

$V$ - que apresente documento de viagem que:

a) não seja válido para o Brasil;

b) esteja com o prazo de validade vencido; ou

c) esteja com rasura ou indício de falsificação;

VI - que não apresente documento de viagem ou documento de identidade, quando admitido; de visto;

VII - cuja razão da viagem não seja condizente com o visto ou com o motivo alegado para a isenção

VIII - que tenha, comprovadamente, fraudado documentação ou prestado informação falsa por ocasião da solicitação de visto; ou

IX - que tenha praticado ato contrário aos princípios e objetivos dispostos na Constituição Federal.

Parágrafo único. Ninguém será impedido de ingressar no País por motivo de raça, religião, nacionalidade, pertinência a grupo social ou opinião política." 
§ 3 o Condições específicas de repatriação podem ser definidas por regulamento ou tratado, observados os princípios e as garantias previstos nesta Lei.

$\S 40$ Não será aplicada medida de repatriação à pessoa em situação de refúgio ou de apatridia, de fato ou de direito, ao menor de 18 (dezoito) anos desacompanhado ou separado de sua família, exceto nos casos em que se demonstrar favorável para a garantia de seus direitos ou para a reintegração a sua família de origem, ou a quem necessite de acolhimento humanitário, nem, em qualquer caso, medida de devolução para país ou região que possa apresentar risco à vida, à integridade pessoal ou à liberdade da pessoa."

A notificação à Defensoria Pública quando a repatriação imediata não seja possível, evita precisamente a criação de locais de exceção e anomia jurídica como o "Conector", nos quais pessoas têm sua liberdade de ir e vir tolhida e sua vida regida e decidida unicamente por uma autoridade soberana. A Defensoria Pública e, portanto, o Judiciário passam a ter notícia dos estrangeiros que estão aguardando sua repatriação e, assim, passam a poder monitorar, fiscalizar e atuar para que os direitos humanos dessas pessoas não sejam violados.

Apesar do avanço e do potencial protetivo representado por essa previsão, a nova Lei de Migração tampouco é impassível de críticas, visto que deixou de avançar em alguns pontos cruciais no que se refere a situações como as vividas no Conector de repatriação sumária indevida.

O Anteprojeto realizado por especialistas de direitos migratórios ${ }^{46}$ previa que, quando houvesse a inadmissão de qualquer estrangeiro no território nacional,deveria haver a imediata comunicação à Defensoria Pública da União, o que resolveria ambos problemas de anomia jurídica encontrados no "Conector" e também de repatriação sumária indevida dos estrangeiros. Este foi um ponto de tensão durante a tramitação do projeto, sendo que, inclusive, qualquer menção à comunicação à Defensoria Pública da União chegou a ser excluída durante a primeira versão do Projeto de Lei 2516/2015 ${ }^{47}$ enviada à Câmara dos Deputados e reintroduzida posteriormente, porém com redação limitada aos casos de refúgio e que a repatriação imediata não pudesse ocorrer.

\footnotetext{
${ }^{46}$ BRASIL, Anteprojeto do Projeto de Lei de Migrações. Disponível em :http://reporterbrasil.org.br/documentos/anteprojeto.pdf. Acesso em 16 abr 2017

${ }^{47}$ BRASIL. Projeto de Lei 2516/2015. Disponível em

http://www.camara.gov.br/proposicoesWeb/fichadetramitacao?idProposicao $=1594910$
} 
Sendo a decisão do agente de imigração uma decisão administrativa que acaba por ser de fato irrecorrível, isto pode significar muitas vezes, como já mencionado, uma violação aos direitos humanos de possíveis solicitantes de refúgio, especialmente a se considerar que a Polícia Federal tem mostrado não ser o órgão mais indicado a fazer tal análise meritória e a acolher estrangeiros em situação de vulnerabilidade.

\section{CONSIDERAÇÕES FINAIS}

Os casos de violações de direitos humanos no espaço denominado "Conector", no Aeroporto Internacional de Guarulhos, enunciam uma prática desumanizadora dos estrangeiros em trânsito. As violações de seus direitos humanos perpassam por dois graves problemas primordiais: o cerceamento de sua liberdade sem base legal regulamentando-o e sem acesso a uma autoridade judiciária, bem como a repatriação sumária de indivíduos que poderiam ser enquadrados como solicitantes de refúgio e que, muitas vezes, correm perigo em seus países de origem.

A falta de regulamentação no ordenamento jurídico da detenção dos estrangeiros inadmitidos criava um espaço de anomia jurídica, no qual a Polícia Federal executava uma função soberana sobre a vida humana daqueles indivíduos. Sua detenção, as condições a eles impostas, seu destino, sua repatriação ou sua eventual solicitação de refúgio estavam sujeitos a ato discricionário subjetivo da autoridade policial, o que é preocupante dado que o estrangeiro costuma ser visto sob um ponto de vista protecionista de ameaça à segurança nacional e não como sujeito de direitos.

Esse discurso da periculosidade dos indivíduos como forma de legitimar a suspensão total ou parcial de seus direitos já era há muito apontado como problemático pelo filósofo Giorgio Agamben. Tal suspensão de direitos submetia a vida humana à exceção, levando-a, impreterivelmente, a algum tipo de "campo". No "campo", assim como no "Conector" na modernidade, não vige o ordenamento jurídico, e a vida humana está única e exclusivamente à mercê do poder soberano, in casu, representado pela Polícia Federal.

Outra evidência de que os estrangeiros no "Conector" encontram-se destituídos de quaisquer direitos é o fato, já abordado pela filósofa Hannah Arendt em suas pertinentes análises, de que o cometimento de um pequeno delito melhoraria sua situação fática, ao 
transformá-los de indivíduos sem qualquer status jurídico em indivíduos, ainda que de forma anacrônica, protegidos pelo Direito Penal.

É nesse ponto que as reflexões filosóficas são vitais no que se refere à formulação de pensamento crítico sobre os comportamentos violadores de direitos humanos. É fácil chocarmo-nos com os horrores perpetrados ao longo da história, porém há uma imensa dificuldade em enxergar que continuamos a repetir os mesmos padrões de violações aos direitos humanos dos indivíduos sob as mesmas justificativas protecionistas de segurança nacional.

A nova Lei de Migração (Lei 13.445/17) trouxe mudanças interessantes nesse sentido, que podem representar avanços no que se refere aos direitos dos estrangeiros em trânsito

Em tese, a princípio, com a comunicação à Defensoria Pública da União nos casos de refúgio e quando impossibilitada a repatriação sumária, se resolve a problemática referente à existência de um“campo", porém persiste o fato de que a Polícia Federal é a responsável por realizar a análise meritória acerca de eventual situação de refúgio, sendo necessário manter-se atenção e fiscalização de como tal previsão será aplicada para garantir que os direitos humanos dos indivíduos sejam efetivamente respeitados.

Como já indicava Hannah Arendt, o direito de ter direitos, ou o direito de cada indivíduo de pertencer à humanidade, deveria ser garantido pela própria humanidade, e a dignidade humana que esses direitos outorgam deveria permanecer válida e real mesmo que somente existisse um único ser humano na face da terra.

\section{REFERENCIAS}

RAMOS, Alan Alexandrino (2015), O impedimento e a repatriação de estrangeiros no Brasil e possíveis inconsistências com a convenção americana de direitos humanos, in Revista Migrações, Outubro 2015, n. ${ }^{\circ}$ 12, Lisboa: ACM, pp. 137-156. Disponível em: <http://www.om.acm.gov.pt/documents/58428/340194/pp137-156_artigo6.pdf/c252b8dd-93a8-4254-9243-0dec335b942f) >. Acesso em: 16 abr 2017.

BRASIL, Decreto Lei $n^{o}$ 86.715/81, de 10 de dezembro de 1981. Disponível em: $<$ http://www.planalto.gov.br/ccivil_03/decreto/antigos/d86715.htm>. Acesso em: $16 \mathrm{abr}$ 2017.

BRASIL. Lei 6.815/80, de 19 de agosto de 1980. Disponível em: <http://www.planalto.gov.br/ccivil_03/leis/L6815.htm> . Acesso em: 16 abr 2017. 
BRASIL, Lei $n^{o}$ 9474/97, de 22 de julho de 1997. Disponível em: <http://www.planalto.gov.br/ccivil_03/leis/L9474.htm. >. Acesso em: 16 abr 2017.

CHIARETTI, Daniel. Breve Análise da Detenção Migratória no Brasil. Carta Capital. 29 de outubro de 2015.2 Disponível em: $<$ http://justificando.cartacapital.com.br/2015/10/29/breve-analise-da-detencaomigratoria-no-brasil/>. Acesso em: 16 abr 2017.

Convenção Relativa ao Estatuto dos Refugiados, adotada em 28 de julho de 1951, no âmbito das Nações Unidas. Disponível em: $<$ http://www.acnur.org/t3/fileadmin/Documentos/portugues/BDL/Convencao_relativa _ao_Estatuto_dos_Refugiados.pdf > Acesso em: 16 abr 2017.

BRASIL. Secretaria Nacional de Justiça (SNJ). Manual de extradição. Brasília: Secretaria Nacional de Justiça (SNJ), Departamento de Estrangeiros, 2012. Disponível em: $<$ https://www.justica.gov.br/sua-protecao/cooperacao-

internacional/extradicao/arquivos/manualextradicao.pdf > . Acesso em: 16 abr 2017.

Acordo melhora atendimento a refugiados no Aeroporto de Guarulhos. Agência Brasil. 28 de janeiro de 2015.2 Disponível em: <http://agenciabrasil.ebc.com.br/internacional/noticia/2015-01/acordo-melhoraatendimento-refugiados-e-estrangeiros-no-aeroporto-de>. Acesso em: 16 abr 2017.

Relatório Operacional do Aeroporto Internacional de Guarulhos. Disponível em: <https://www.gru.com.br/pt/RelatorioOperacional/2016-12.pdf. $>$. Acesso em: 16 abr 2017.

ASANO, Camila. Migrantes em Guarulhos. Conectas Direitos Humanos. 18 de dezembro de 2014. Disponível em: <http://www.conectas.org/pt/acoes/politicaexterna/noticia/27625-migrantes-em-guarulhos $>$. Acessoem: 16 abr 2017.

UNHCR's Revised Guidelines on Applicable Criteria and Standards relating to the Detention of Asylum-Seekers, p. $3 . \quad$ Disponível em: $<$ http://www.unhcr.org/protection/globalconsult/3bd036a74/unhcr-revised-guidelinesapplicable-criteria-standards-relating-detention.html > . Acesso em 16 abr 2017.

Convenção Americana de Direitos Humanos, de 22 de novembro de 1969. Disponível em: $<$ https://www.cidh.oas.org/basicos/portugues/c.convencao_americana.htm $>$. Acesso em 16 abr 2017.

Pedido LAI à Polícia Federal sobre o espaço Conector no Aeroporto Internacional de Guarulhos. Conectas. Disponível em: <http://www.conectas.org/pt/acoes/justica/lei-deacesso-a-informacao/99-pedido-lai-a-policia-federal-sobre-o-espaco-conector-noaeroporto-internacional-de-guarulhos>. Acesso em 16 abr 2017.

BRASIL. Sistematização da experiência de um ano de funcionamento do posto. Ministério da Justiça, 2007. Disponível em: <http://www.justica.gov.br/sua- 
protecao/trafico-de-

pessoas/publicacoes/anexos/sistematizacaofuncionamentopostohumanizado.pdf

FARIAS, Adriana. Em busca de refúgio, estrangeiro fica 20 dias retido em aeroporto. Folha de São Paulo. 14 de junho de 2014. Disponível em: <http://www1.folha.uol.com.br/cotidiano/2014/06/1470333-em-busca-de-refugioestrangeiro-fica-20-dias-retido-em-aeroporto.shtml> Acesso em 16 abr 2017.

Conector volta a mostrar situação precária de migrantes no Brasil e necessidade de nova lei de migração. Migra Mundo. 29 de setembro de 2016. Disponível em: <http://migramundo.com/conector-volta-a-mostrar-situacao-precaria-de-migrantesno-brasil-e-necessidade-de-nova-lei-de-migracao/>. Acesso em 16 abr 2017.

SANCHES, Mariana. Candidatos a refúgio ficam no limbo em sala do Aeroporto. $O$ Globo. 21 de junho de 2015. Disponível em: <http://oglobo.globo.com/brasil/candidatos-refugio-ficam-no-limbo-em-sala-deaeroporto-16509800>. Acesso em 16 abr 2017.

GODINHO, Luiz Fernando. Acordo melhora atendimento a refugiados e estrangeiros no Aeroporto de Guarulhos. ACNUR. 29 de janeiro de 2015. Disponível em: http://www.acnur.org/portugues/noticias/noticia/acordo-melhora-atendimento-arefugiados-e-estrangeiros-no-aeroporto-de-guarulhos/ . Acesso em 16 abr 2017.

TERESI, Verônica Maria. Guia de referência para a rede de enfrentamento ao tráfico de pessoas no Brasil.Ministério da Justiça, Secretaria Nacional de Justiça, 2012, pág. 37.

LEITE, Larissa. O devido Processo legal para o refúgio no Brasil. Doutorado-Faculdade de Direito, Universidade de São Paulo, Dezembro de 2014. Disponível em http://www.teses.usp.br/teses/disponiveis/2/2140/tde-08042016-145056/pt-br.php.

Acesso em 16 abr 2017.

LESSA, Paula Constantino Chagas. Direitos Humanos do estrangeiro em trânsito. Uma perspectiva entre a soberania e os Direitos Humanos do Estrangeiro em trânsito. Revista Publica Direito. Disponível em $<$ http://www.publicadireito.com.br/artigos/?cod=19a87049ef104ba1 >. Acesso em $16 \mathrm{abr}$ 2017.

SEVERO, Fabiana Galero. O procedimento de solicitação de refúgio no Brasil à luz da proteção internacional dos diretos humanos. R. Defensoria Públ. União. Brasília, DF n. 8 p. 1-356 jan/dez. $2015 . \quad$ Disponível emhttp://www.dpu.def.br/images/stories/escola_superior/arquivos/Revista/revista8/artigo2__fabiana-galera-severo.pdf. Acesso em 16 abr 2017.

Refúgio no Brasil: a proteção brasileira aos refugiados e seu impacto nas Américas / Luiz Paulo Teles Ferreira Barreto, organizador. - 1. ed. - Brasília: ACNUR, Ministério da Justiça, 2010. Disponível em: http://www.acnur.org/t3/fileadmin/Documentos/portugues/Publicacoes/2010/Refugio_no _Brasil.pdf Acesso em 16 abr 2017. 
AGAMBEN, Giorgio. Homo sacer: $O$ poder soberano e a vida nua, I. 2. Ed. Belo Horizonte: Ed. UFMG, 2010.

AGAMBEM, Giorgio. Estado de exceção:[Homo Sacer, II, I]. Boitempo Editorial, 2015.

BRASIL, Projeto de Lei $n^{o} 288$ de 2013. Disponível em: $<$ http://www.camara.gov.br/proposicoesWeb/prop_mostrarintegra;jsessionid=54FCBBA 069993146EDF0AABE5E1FE105.proposicoesWebExterno1?codteor=1366741\&filenam e=PL+2516/2015> Acesso em 16 abr 2017.

Anteprojeto da Nova Lei de Migrações. Disponível em http://reporterbrasil.org.br/documentos/anteprojeto.pdf. Acesso em 16 abr 2017.

ARENDT, Hannah. 1906-1975. Origens do totalitarismo. Tradução: Roberto RaposoSão Paulo: Companhia das Letras. 1989.

Recebido em : 19/09/2017.

Aprovado em: 30/09/2017 